\title{
THE BREAK-IN STAGE OF CYLINDER-RING WEAR: A CORRELATION BETWEEN FIRED ENGINES AND A LABORATORY SIMULATOR
}

\author{
G. C. BARBER and K. C. LUDEMA \\ Mechanical Engineering Department, University of Michigan, Ann Arbor, MI 48109 \\ (U.S.A)
}

(Received May 14, 1986; accepted November 27, 1986)

\section{Summary}

The wear of the piston ring-cylinder wall contact area in fired engines has not been satisfactorily simulated in bench testers so far. This paper reports the development of a successful test device in which the same progression of surface change occurs as in fired engines. These changes were observed by microscopy, by hardness indentations and by the use of the stylus roughness tracer. The test device uses ring and cylinder segments and it oscillates at 350 cycles $\mathrm{min}^{-1}$ over a stroke of $19 \mathrm{~mm}$. It is apparently not necessary to duplicate the temperature, atmosphere, fluid film thickness and other obvious conditions in an engine to achieve simulation. At least, the materials in the engine were not affected by the conditions in the engine that were not duplicated in the laboratory tester.

The purpose in developing the tester was to study the role of the honed roughness pattern found on most cylinder walls. Sevcral engine manufacturers attempt to achieve "plateau honing". No manufacturer polishes new cylinder walls. The reason for the honed roughness is to allow a high wear rate, without catastrophic scuffing, in locations of high stress between poorly conforming parts.

\section{Introduction}

The technology of finishing engine cylinder walls appears to be unique among tribological systems. It is one of the very few lubricated surfaces that is deliberately not made as smooth as economically possible. No accepted theory substantiates this practice. On the contrary, lubrication theory suggests that, for long product life, the surface roughness of sliding elements should be no greater than the thickness of the lubricant film. This would 
require very smooth cylinder walls because the oil film on the cylinder walls must be rather thin to avoid high oil consumption.

The roughness of cylinder walls is not simply that which is left after a casual machining operation. Rather, it is formed by a carefully controlled honing technique. The simplest common explanation for this procedure is that grooves created by honing "store" oil to prevent scuffing and other dire consequences. This explanation is inadequate to explain why cylinder walls function properly when they become very smooth after running for a few hundred hours. A more likely explanation is that the roughness is needed only in the early stages of engine operation to enhance the removal or wearing off of cylinder wall and ring material in places of high interference between these components. They are not made accurately enough to effect good conformity to each other and non-conformity causes excessive blow-by of gases and high oil consumption.

Roughness therefore effects or allows an initial high wear rate. There is obviously some risk in this procedure because at some point in the life of the sliding components the wear rate should diminish in order to effect long component life. Wear mechanisms are not sufficiently understood to be able to design such a sequence from first principles. Successful breaking-in of engines was determined by experiment which involved examining a large number of materials, lubricants, component details and sequences of running of engines. It appears that successful engine building preceded "good tribology". However, the time has come to review the cost of making engines and to reduce or eliminate the break-in stage.

This paper reports the results of a study of only the break-in stage of engine wear. The break-in period refers to a number of changes in engines, namely the early period during which there is high friction, high blow-by or high oil consumption. There is no general agreement on whether these are coincident events and no agreement on which is the more crucial condition to correct in order to have a run-in or "broken-in" engine. The main emphasis in this paper is on the changes in the surface of cylinder walls of fired engines. 18 engines were used in the study. In parallel with this study, an engine simulator was built so that a number of test variables could be tried without the need to use full-scale engines. The simulator is very simple and emulates a few of the obvious conditions of engine experience. However, we believe that the device is a true simulator of the fired engines because the simulator and the engines produced identical changes on the cylinder surface during operation and in the same order. Before describing the research, a perspective is given on the wearing of engines, the materials used in making them and the desired surface roughness.

\section{Engine cylinder wear}

The wearing of piston rings and cylinder walls may be divided into three regimes or types. 


\subsection{The break-in stage}

Material loss is primarily from the upper part of the cylinder and from the top compression ring. It occurs primarily in the cylinder at the top dead center (TDC) of piston ring travel. Excessive surface damage at this stage is often referred to as scuffing but it is not uniquely described by this term.

\subsection{The progressive wear stage}

The cylinder may wear more at TDC than elsewhere [1 - 4] but there is measurable wear all over. The piston rings rather than the piston are the main cause of cylinder wear. There is higher wear at TDC than elsewhere because it is the location of the highest contact pressure, the location of the greatest concentration of acids and the location of the thinnest lubricant film. On the latter point, there have been several attempts to calculate [5 - 8] and measure $[4,9,10]$ the lubricant film thickness between piston rings and cylinder wall. The film thickness beneath the top compression ring at TDC was found to be very small, in the range $0-3.0 \mu \mathrm{m}$, because of the low sliding velocity at that location. The maximum oil film thickness was found near the center of the stroke where the maximum speed is reached. This applies, of course, to the condition of normal running. All engines that stop and start do so with very thin lubricant films at all locations. For perspective on the influence of oil films, Gumbleton [11] found that $75 \%$ of the total wear which took place during a $2 \mathrm{~h}$ run occurred in the first $6 \mathrm{~min}$.

Cylinder wear in the progressive stage may occur by several mechanisms but mostly by abrasion and corrosion. Some abrasive wear is caused by particles left in the engine during manufacture and assembly [12]. This is correctible by proper cleaning during the various stages of manufacture [13]. A form of abrasion may result from debris accumulated from various wear mechanisms. However, dust from the intake air or dirt in the lubricating oil probably causes most of the abrasive wear.

Corrosion was found by Williams [14] to be important, particularly under cold-running conditions, i.e. when the products of combustion condensed on the cylinder walls. The acidic condensate causes high wear rates by corrosion [15 - 17]. This mode can be reduced by using thermostats so that engines spend less time running at low temperatures and by the use of acid-buffered lubricants $[18,19]$.

A mechanism of wear by formation and removal of oxides should also be included in the list. This mode of wear is seen in the wear of lubricated steel but it has not been reported to occur in engines.

\subsection{A catastrophic mechanism}

Catastrophic wear can occur in a well-functioning engine if some unusual events take place. This may be due to high temperature, high loads, interruptions of oil supply or intake of large quantities of contaminants. The result is a type of damage along much of the length of the cylinder and piston, widely referred to as scuffing $[20,21]$. The outward signs of severe scuffing in an engine are high oil consumption and blow-by; if the scuffing is 
allowed to continue, seizure will often result. This is the type of scuffing that is most often reported in the literature. In fact, scuffing is usually defined in terms of the latter stages of damage. Dyson [22], in a review of scuffing, subscribes to the Institution of Mechanical Engineers' definition of scuffing as "gross damage characterized by the formation of local welding between the sliding surfaces". In the present work scuffing will have a broader meaning, encompassing all of the events originating on the scale of a single asperity and extending to any point of macroscopic manifestation up to seizure. Scuffing will not be defined in terms of "welding" but rather in terms of "a roughening of surfaces by plastic flow whether or not there is material loss or transfer" [23].

One of the standing mysteries in the scuffing of engine parts is the existence of the "white layer". Clayton and Jenkins [24] found a white layer during the running-in of the piston rings in a mineral-oil-lubricated aeroengine. Rogers $[25,26]$ also observed it on the worn rings and liners taken from diesel engines. He apparently saw two types of white layer, the W-1 and the W-2 types, the latter of which was found on cast iron cylinder liners. He asserted that scuffing is caused by the continuous production and spalling off of this W-2 surface layer which form abrasive debris and which cause further wear. Eyre and Dutta [27] speculate that the production of a white layer is a result of scuffing and not the cause of scuffing.

The white layers on the tribological surfaces of steels and cast irons have been widely studied [28 - 32]. There is no general agreement on the composition of the layers but all authors report them to be very hard and resistant to etching. Wiborg [29] reported that the white layer in cast iron is five times as hard as the bulk iron and it appears to have a mixed composition, being a dispersion of white-etching particles in a dull grayish matrix. By etching with different etchants he thought that the white particles were cementite because they appeared white in Nital etch and brownish in sodium picrate etch just as cementite does. The grayish phase does not resemble any known iron phase.

Scuffing is thought by some authors to be initiated by thermal bumps, which are asperities that expand owing to local heating. Aue [33, 34] and Burton and coworkers [35, 36] developed equations based on the thermal bump theory that should be capable of predicting the danger of scuffing for a given system.

\section{The mechanics of breaking-in of cylinders and rings}

It is well known that machinery is likely to either fail early or last a long time. The probability of a long life is enhanced by careful operation at the beginning of service.

For piston rings and a cylinder wall, one of the first investigators to suggest the necessity of a break-in period was Teetor [37]. He stated that initial wear of a "not-too-destructive" type is the great compensator for the 
inability to eliminate the difficulties in producing the ideal piston ring and cylinder combination. Sreenath and Raman [38] observed the wear rates and the surface roughness changes of the cylinder wall of a single-cylinder diesel engine during breaking-in. They speculated that, in the early stages of breaking-in, the surfaces are smoothed mainly by the removal of material from the tops of asperities. However, the asperities were originally of a 0.48 $\mu \mathrm{m}$ center-line average height whereas an average of $2.1 \mu \mathrm{m}$ of material was worn away before the flat tops were seen. This suggests that the action of the piston rings is to develop new asperities well below the level of the hone marks. Montgomery [39] examined the surfaces of cast iron cylinder liners after break-in. He found that the portions of the cylinder liners that had contacted the piston rings were considerably smoother than the unworn portion of the cylinder. The worn portion of the cylinder was also found to be covered with a surface layer which Montgomery believed to be composed of graphite and $\mathrm{Fe}_{3} \mathrm{O}_{4}$. He further suggested that the smoothing during break-in is primarily due to this surface layer rather than the wearing off or squashing of asperities.

For components other than engines there have been other illuminating papers. Hirst and Lancaster [40] suggested that the generation of a (unspecified) protective surface film is an essential part of the breaking-in of machinery. Sugishita and Fujiyoshi $[41,42]$ found that the friction and wear behavior of cast iron is influenced by the formation of a surface layer which was assumed to be composed of graphite. Kang and Ludema [43] reported the results of scuffing tests using cylindrical bearings sliding on flat steel specimens. They found that, at the beginning of sliding, metallic debris formed, apparently owing to low cycle fatigue. Simultaneously, a soft and ductile film composed of $\mathrm{Fe}_{3} \mathrm{O}_{4}$ was formed on the steel surface. They described early sliding as competition between the rate of oxide formation and the rate of oxide removal by the metallic debris particles. If the oxide prevails, successful break-in is said to have occurred.

\section{The materials in cylinders and piston rings}

The main subject in this investigation is cylinder wall wear. However, the piston ring face, the lubricant and the cylinder wall constitute a tribological system. Therefore, to consider properly the problem of cylinder wear, the piston ring must also be studied.

Piston rings are most commonly made of gray cast iron. The most successful material appears to be a pearlitic iron, containing type A graphite in the size range 3 - 5 (ASTM) [44], some phosphide eutectic and no more than $5 \mathrm{wt} . \%$ free ferrite. Piston rings are often treated or coated with various substances, including iron oxide, chromium and molybdenum [45 - 48].

Most engine cylinders in use today are also made of pearlitic gray cast iron. Jackson [49] is of the opinion that cylinders as well as rings should contain no more than $5 \mathrm{wt} . \%$ free ferrite in the surface, to prevent adhesion 
to the rings. To limit free ferrite formation, it is possible to use small amounts of tin or chromium [44], hold the amount of silicon to a minimum [29] and use up to $0.8 \mathrm{wt} . \% \mathrm{Cu}[50]$. Many investigators also recommend that some phosphide eutectic should be present in the microstructure to ensure good wear resistance but reasons are usually not given for this recommendation. Type A flake graphite of ASTM size 4 - 7 is often recommended $[3,29,51]$ for good wear resistance but again the reasons are not known. Large and isolated particles of cementite have been found to be detrimental to engine life [52].

The most extensive work done to determine the effect of metallurgy on cast iron cylinder liners for diesel engines was carried out by LaBelle [51]. These tests utilized 550 cylinder sleeves, 360 pistons and 2150 compression piston rings. Two types of tests were performed. The first test used a threecylinder engine to evaluate scuff resistance based on the severity of operation necessary to produce scuffing. The second test used a six-cylinder engine to evaluate normal wear resistance in $1000 \mathrm{~h}$ of engine operation on a controlled cycle. The following are some of the results of this investigation.

(1) The chemical composition of iron does not affect the wear resistance unless the graphitic or metal matrix microstructure is affected by such composition. Thus cast iron should be specified by microstructure with the composition a secondary consideration.

(2) A good starting point in specifying the metallurgy for an engine cylinder is a pearlitic matrix, type A graphite, graphite size $4-6$ and a hardness of $200-250$ Brinell.

These are the results from one large study which, unfortunately, are not universally applicable or relevant. The literature contains very much confusing and sometimes conflicting information on how to improve the wear resistance of cylinders and piston rings. Aue [33] believes that for every reference showing a beneficial influence of a factor there is at least one other reference showing the same factor to be detrimental to cylinder wear resistance!

\section{Surface finishing and honing of cylinder walls}

Conner $[53,54]$ was one of the first investigators to find a direct relationship between cylinder wall surface roughness and engine performance. Breaking-in occurred in much less time with fine-honed surfaces than with the rougher reamed surfaces. This was carried out in the mid $1930 \mathrm{~s}$, in the early days of development of the stylus tracer method of surface roughness measurement.

Apparently, a number of manufacturers used the honing process, perhaps as much for size and roundness of cylinders as for surface roughness. The details of the surfaces were not carefully investigated for over 25 years. In 1963 Hesling [55] tested a wide variety of automotive and truck engines in order to develop specifications for cylinder wall roughness to achieve rapid break-in and good oil economy. Some of these specifications were as follows. 
(1) A plateau roughness should be formed with the plateau being 1/2 $2 / 3$ of the surface.

(2) The plateau roughness should be formed in a uniform overlapping spiral pattern forming angles of $22^{\circ}-32^{\circ}$ off the tangential direction.

(3) The grooves in the surface should be clean and free of torn and folded metal.

(4) A roughness of $0.5 \cdot 0.75 \mu \mathrm{m}$ AA should be achieved.

Later authors agree with these specifications and generally agree that the reason is to achieve quick and effective break-in [56, 57]. Although most authors give assent to the concept of suppressing high local pressure points and reducing the initial amount of wear debris, no one proves these points. The progression of breaking-in on a microscopic scale must therefore be considered unresolved.

\section{Simulating engine cylinder wear}

Materials and lubricants are definitively tested in automobiles in the hands of the consumer. However, this is a costly and time-consuming procedure, particularly when one small part of an engine is to be monitored. Thus reliable laboratory testers or simulators are very attractive but their use leads to a paradox. It is usually not possible to study the engine cylinder wear of fired engines using microscopes without cutting the cylinder apart, thus making it impossible to restart the engine and continue testing for the study of the progression of wear. The simulator, however, can usually not simulate all of the conditions that prevail in a fired engine.

There have been several attempts to simulate the tribological behavior of piston rings and engine cylinders. Eilon and Saunders [58], de Faro Barros and Dyson [59], Tischbein [60] and others [61 - 63] have developed special test machines to study the tribological behavior of piston rings and cylinder walls. Most investigators attempt to achieve the same operating conditions in their test machine as occur in real engines but they usually fail.

One new approach was used in separate tests by Rogers [26] with a pinon-dise machine and Wiborg et al. [29] with a reciprocating test simulator. They both defined "valid simulation" to occur when a "white layer" formed, similar to that found on the scuffed surfaces on cylinder walls. This would appear to be a stronger criterion for simulation than to match as many conditions of machine operation as can be imagined to occur. However, the relationship between white surface layer formation and cylinder wall scuffing is not understood. Therefore a simulation based on white surface layer formation may not be useful.

Wear debris is another possible indicator of a valid simulation. This technique has the main advantage of not having to disassemble either the test system or the practical system. However, we cannot always be certain of the origin of the debris and further study is required to relate properly the size and shape of wear debris to the type of wear that occurs on surfaces. In this 
work we have taken the position that the worn surface is the best indicator of the progression of wear. The experiments therefore involve microscopic observations of cylinder wall surfaces at various stages of wear.

\section{Experimental details}

In the present work the first level of simulation of engine service was achieved in a laboratory bench tester. The work proceeded as follows.

(1) The simulation began with a microscopic examination of the cylinder walls and piston rings of conventional gasoline fueled engines, run both on the road and in dynamometer tests. A clear pattern of surface change during the running of engines was inferred.

(2) Engine materials were placed into a laboratory device, described below and tested over a range of available variables. Test conditions were found, by trial and error, that produced the same progression of surface change with time of testing as seen in fired engines made of iron. This device was thus considered to be an adequate simulator of engine service.

\section{The laboratory simulator}

An oscillating test machine has been constructed which has a stroke of $19 \mathrm{~mm}$, with the capability of applying various nominal contact pressures up to $70 \mathrm{MPa}$ and reciprocating rates up to 15 cycles s$^{-1}$. A sketch of this device is shown in Fig. 1. Small segments of cylinder liners were used in the test machine and they were periodically removed from the test machine and examined using optical microscopy and scanning electron microscopy. Figure 1(a) shows the mechanisms used to oscillate the cylinder liner specimen. Figure 1(b) shows the piston ring support and load application system and Fig. 1(c) gives a cross-sectional view that shows how the piston ring is supported. The piston rings used in all tests were molybdenum-"filled" rings used by Cadillac for their top piston ring. Every $3 \mathrm{~min}$, during testing, 0.04 $\mathrm{ml}$ of lubricant was dripped on the surface of the cylinder liner specimen.

\section{Results of the study of cylinder walls}

18 cylinder liners were taken from Cadillac and Chevrolet engines which had been operated (fired) over a range of time and distance from $20 \mathrm{~min}$ to 94000 miles. General observations and measurements were made from these cylinders but five cylinders were particularly useful for describing the progression of the surface change seen in all engines. These were from the following types of engines.

(1) Cadillac run for $20 \mathrm{~min}$ on a dynamometer.

(2) Cadillac run for $15 \mathrm{~h}$ on a dynamometer. 


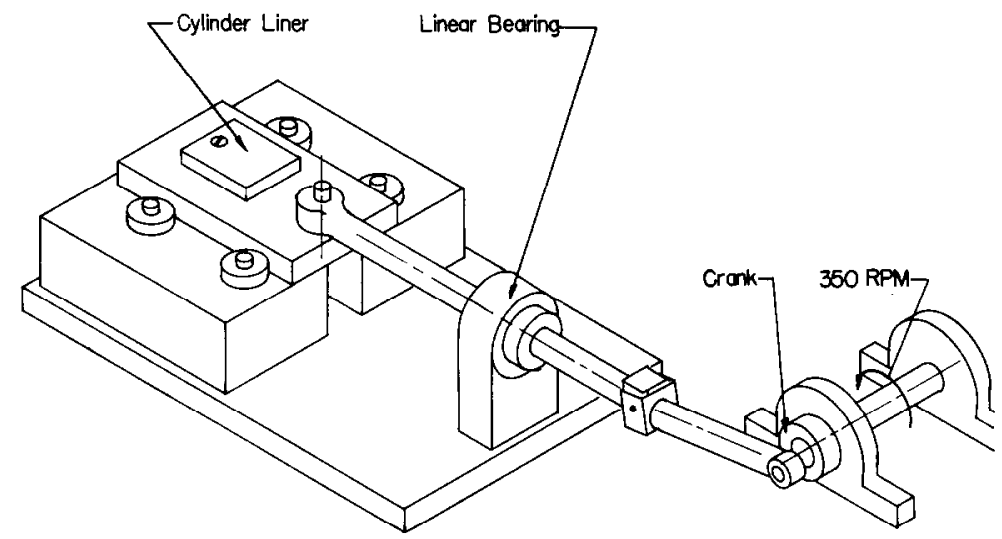

(a)
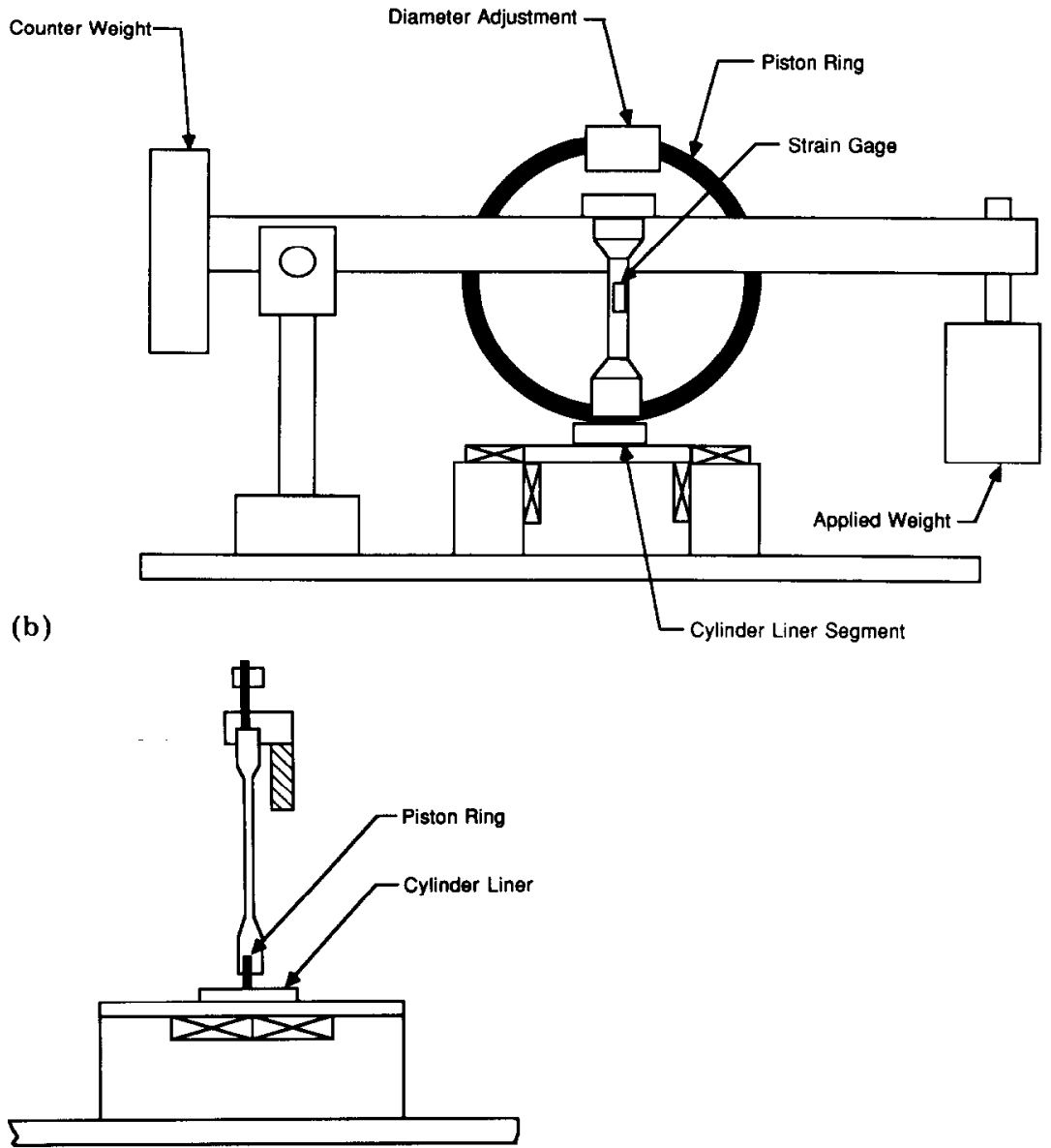

(c)

Fig. 1. (a) Mechanisms used to oscillate the cylinder liner specimen. (b) Piston ring support and load application system. (c) Cross-section of piston ring support. 
(3) Cadillac given a 16000 mile controlled road test.

(4) Cadillac given a 72000 mile controlled road test.

(5) 1971 Chevrolet pickup truck, run for 94000 miles in commercial service.

All cylinders were composed of coarse pearlitic gray iron and had hardness of approximately 250 Knoop hardness or about 85 HRB. (The molybdenum surface of the piston rings has a hardness of about 370 Knoop.) The cylinders were prepared by boring and honing with the standard spiral scratch pattern. It was not possible to run a cylinder for a few hours, examine it and return it to service and examine it again. Thus each of the cylinders constitutes the end point of a different experiment. However, the similarity in the microstructure of all cylinders and the clear trends seen in the cylinder walls as a function of running time were taken as indicating sufficient control of experiments for the present purposes.

The surface roughness and general surface topography of several cylinder walls were measured with a surface tracer system. The surface roughness of the original cylinder was usually in the range $0.20-0.25 \mu \mathrm{m} R_{\mathrm{a}}$. After long use and in the most worn regions the roughness was found to be in the range $0.10-0.11 \mu \mathrm{m} R_{\mathrm{a}}$. Figures 2 and 3 show the wear profile of the engine
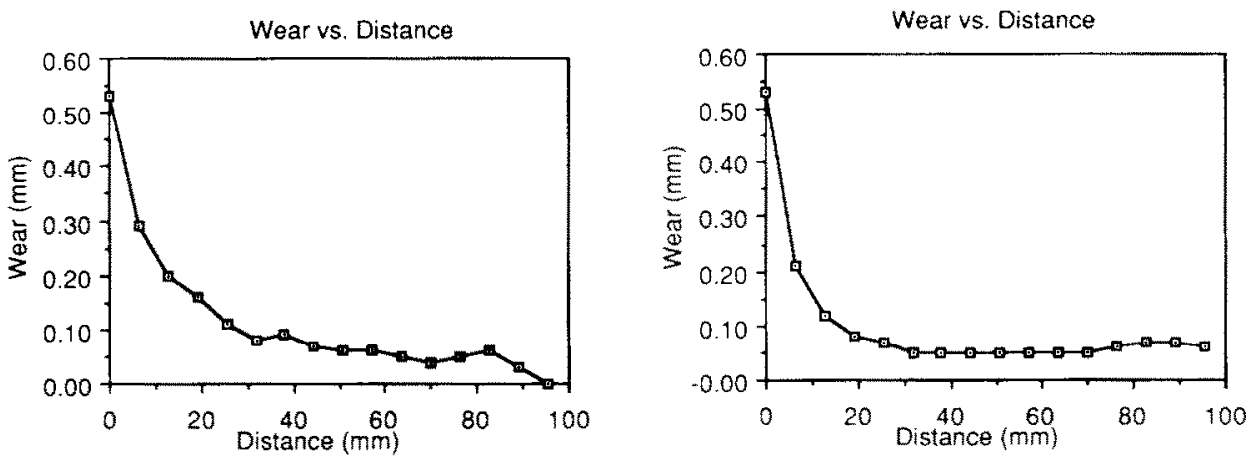

Fig. 2. Diametral wear of cylinder bore, 1971 Chevy pick up run for 94000 miles, thrust direction: $0=$ TDC; 95.25 = bottom dead center.

Fig. 3. Diametral wear of cylinder bore, 1971 Chevy pickup run for 94000 miles, nonthrust direction: $0=$ TDC; $95.25=$ bottom dead center.

run for 94000 miles in the thrust and non-thrust (perpendicular to thrust) directions respectively. The wear was measured using a dial bore gauge and was determined by comparing the diameters measured within the piston ring travel with the diameter at the top of the cylinder where no wear had occurred. The maximum wear depth can be seen to be approximately $0.5 \mathrm{~mm}$ in both the thrust and the non-thrust directions. This is a factor of about 1000 times the asperity height of the original surfaces.

Figures 4 and $6-10$ show cylinder walls as they appear in the scanning electron microscope. Figure 4 shows an unused surface with the original 


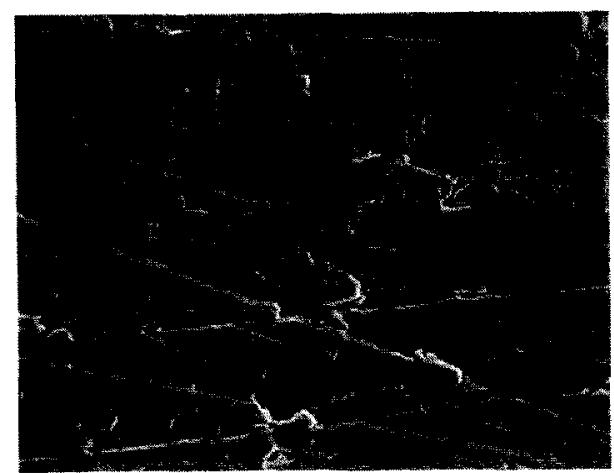

Fig. 4. Unworn Cadillac cylinder liner (magnification 265x).

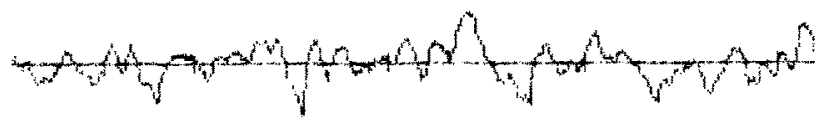

Fig. 5. Surface trace of an unworn Cadillac cylinder wall surface. Horizontal magnification $106 \times$. Vertical magnification $2650 \times$.
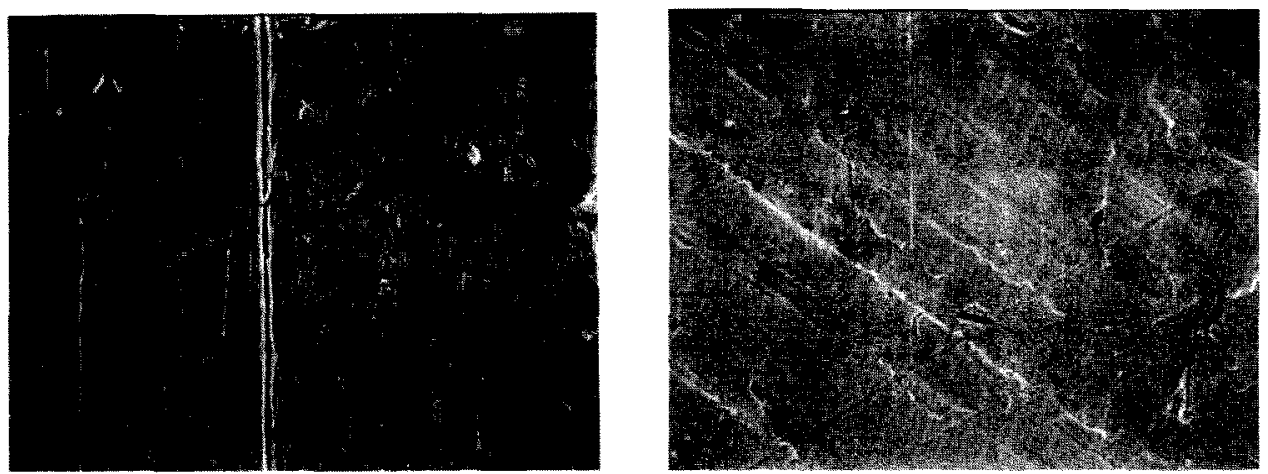

Fig. 6. Run for 20 min (magnification $265 \times$ ).

Fig. 7. Run for $15 \mathrm{~h}$ (magnification $265 \mathrm{x}$ ).

scratch marks from the honing operation. Figure 5 is the reproduction of the surface topography of an unworn Cadillac cylinder obtained by a surface tracer. The remaining figures show the progression of surface change during running. From these observations a pattern of wear became evident. The grooves made by the hone should be noted, which is a pattern deliberately and carefully made in manufacture. It also should be noted that alongside these grooves there are ridges that have been ploughed aside by the abrasive (honing) operation.

Since a progression of wear on one small area of surface could not be obtained we have prepared a schematic series of "micrographs" to illustrate our observations. These are shown in Figs. 11 - 19. In the very first stages of operation the piston ring picks up some ploughed metal and uses it as a 

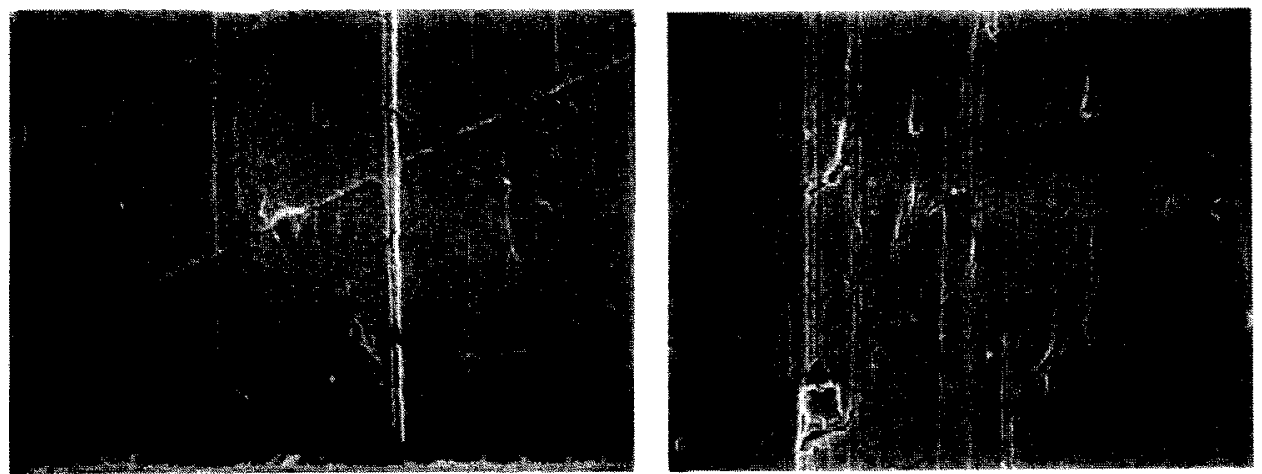

Fig. 8. Run for 16000 miles (magnification $265 \times$ ).

Fig. 9. Run for 72000 miles (magnification $265 \mathrm{x}$ ).

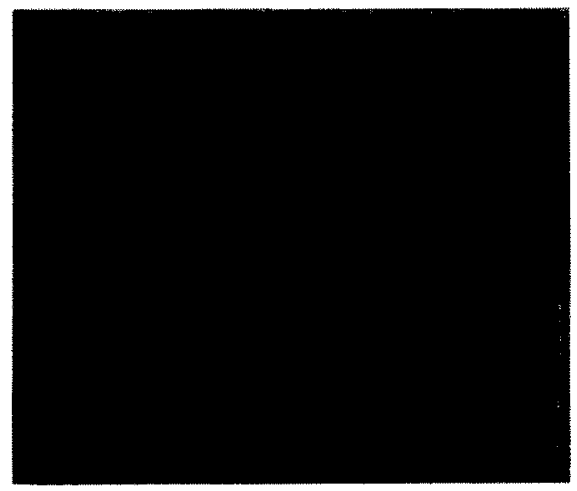

Fig. 10. Run for 94000 miles (magnification 265X).
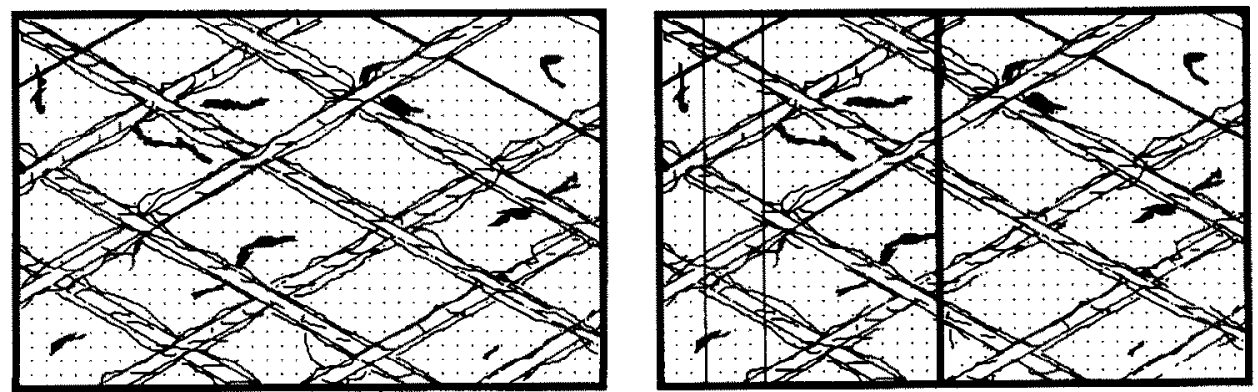

Fig. 11. Simulated micrograph at $302 \times$ magnification of a honed cylinder wall. The surface is smooth between grooves. Ploughed metal is attached to the sides of the grooves. The curved dark lines represent graphite flakes.

Fig. 12. Simulated micrograph at $302 \times$ magnification. After a few minutes of sliding the piston ring loosens some metal from the edges of the grooves and the resulting debris "scratches" vertical grooves on the cylinder wall. 

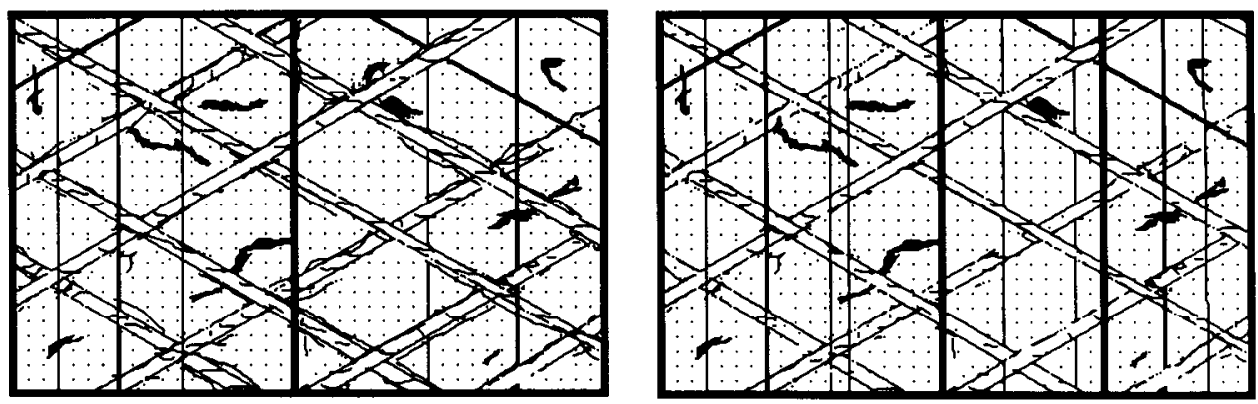

Fig. 13. Simulated micrograph at $302 \times$ magnification. After more sliding there are more vertical grooves and less metal attached to the sides of the grooves.

Fig. 14. Simulated micrograph at $302 \times$ magnification. Most of the edge material has been removed.
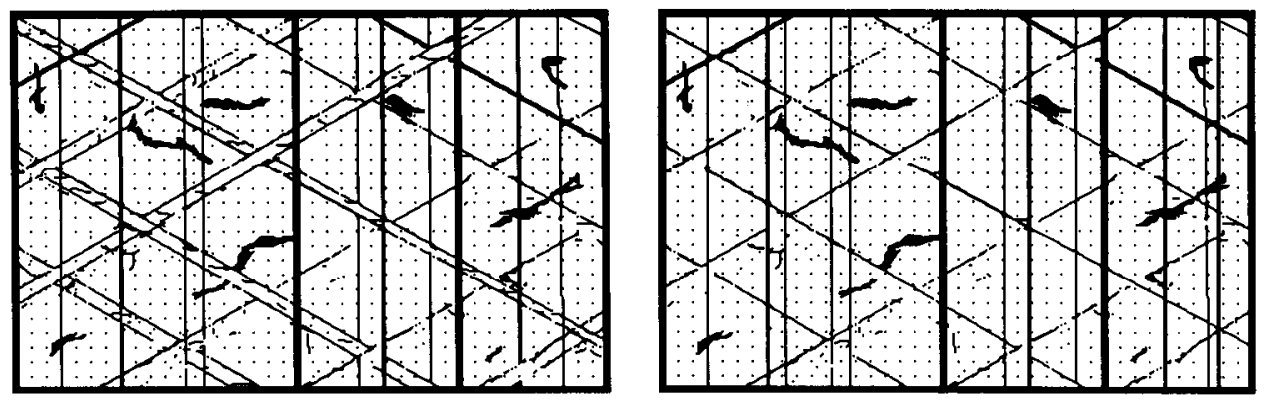

Fig. 15. Simulated micrograph at $302 \times$ magnification. The hone marks are becoming shallow owing to wear.

Fig. 16. Simulated micrograph at $302 \times$ magnification. Some hone marks have disappeared.
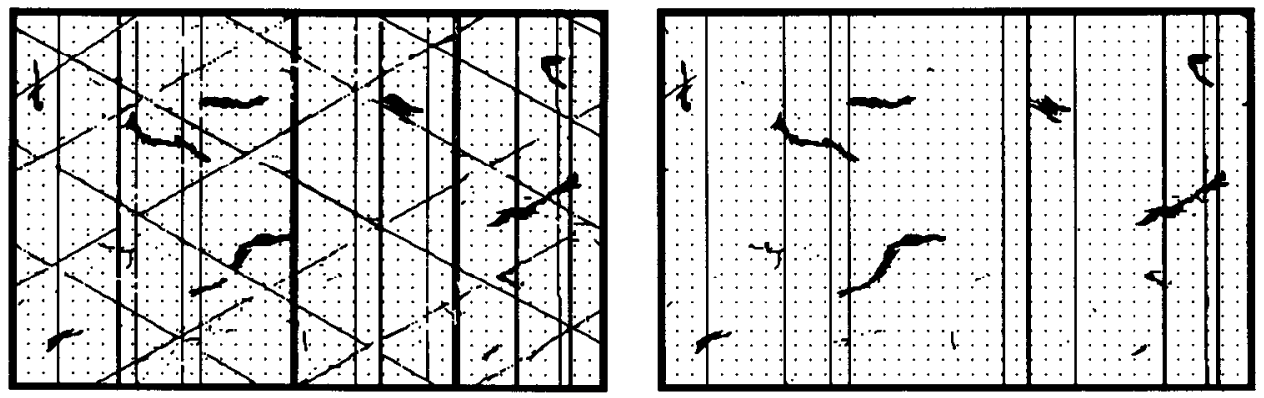

Fig. 17. Simulated micrograph at $302 \times$ magnification. Some vertical scratch marks have become shallow.

Fig. 18. Simulated micrograph at $302 \times$ magnification. The hone marks are no longer visible.

grooving indenter, making the vertical scratches in the cylinder wall. With further operation these scratches grow in depth and number while the original ploughed metal is progressively removed. Eventually, all of the ploughed metal is removed and the cylinder is left with mostly the vertical scratches. 


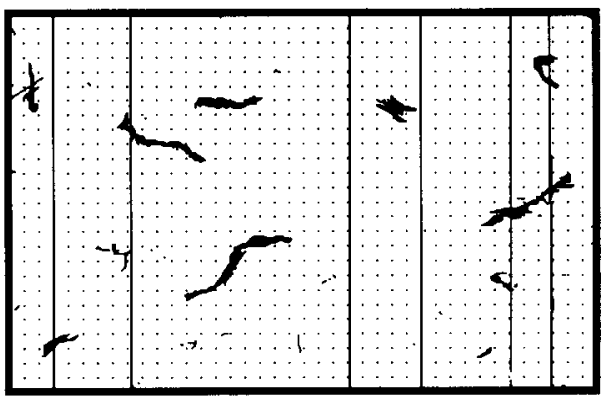

Fig. 19. Simulated micrograph at $302 \times$ magnification. A well-worn cylinder surface.

After still further operation the vertical scratches also are worn away. This may all occur in about 15000 miles or less and at this point the surface roughness is approximately $0.10 \mu \mathrm{m} \mathrm{AA}$. In the background of all sketches there are dark lines that represent the flake graphite in the iron. Actually, the graphite flakes are not as prominent in new engines as in well-used engines, probably because boring and honing smears metal over the graphite flakes.

A dark-brown surface layer was seen to form on all cylinder walls during the first few hours of engine operation. This surface layer (Fig. 20) was confined mainly to the region of the cylinder wall from the TDC position of the top compression ring to the TDC position of the second compression ring.

Below the TDC position of the second compression ring vertical scratches appeared on the cylinder wall in the first few minutes of operation. After these vertical scratches appeared there seemed to be relatively little wear in this region of the cylinder throughout the life of the cylinder. Figure 21 shows that the original hone marks were intact even after an operation distance of 72000 miles.
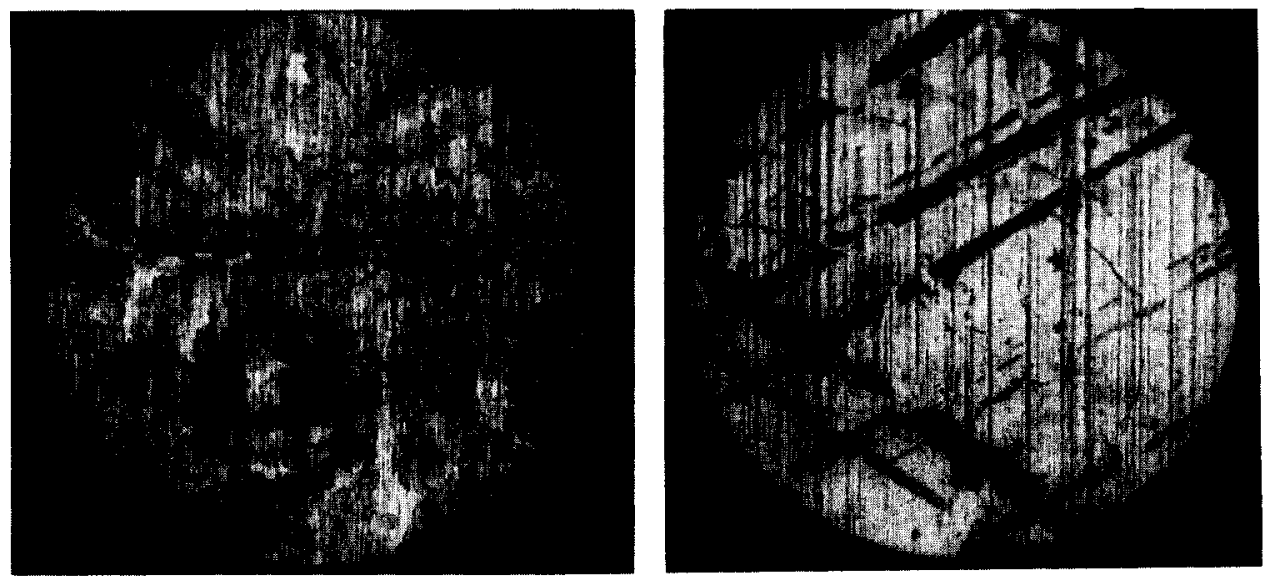

Fig. 20. Run for $15 \mathrm{~h}$. Location shown is at the TDC position of the top ring (magnification $202 x$ ).

Fig. 21. Run for 72000 miles. Location shown is at midstroke (magnification 202x). 
One puzzling observation is that there are often uniform long scratches on the thrust side of the cylinder, extending well below the lowest ring travel. These must be due to particles moved by the piston skirt as well as the rings and do not appear to be a major mode of wear. This condition was not simulated.

\section{Results from the simulator}

Tests were performed at various loads and speeds to find conditions that replicate the wear sequence observed in fired engines. The progression of surface damage on the liner was found to be insensitive to speed in the range available. Therefore a speed of 350 cycles $\mathrm{min}^{-1}$ was selected for use in all tests because this speed produced minimum vibration.

A total of 35 tests were run with a range of constant load and with each test lasting a minimum of $2 \mathrm{~h}$. Periodically, during the test, the simulator was stopped and the appearance of the worn surface was observed. At the conclusion of each test the specimen surface was studied using optical microscopy and scanning electron microscopy. The resulting photographs were then compared with the photographs obtained from the study of fired engines. These test results are summarized in Table 1. The same general trends are seen when using either mineral oil or commercial motor oil. At very low loads, producing pressures below $100 \mathrm{kPa}$, no surface damage is seen on the cylinder liner surface.

In all of the tests performed at loads above $100 \mathrm{kPa}$ scratches appeared within the first few minutes of testing. However, at loads above $300 \mathrm{kPa}$ when using mineral oil and above $700 \mathrm{kPa}$ when using engine oil, surface

\section{TABLE 1}

Summary of results of constant load tests

\begin{tabular}{|c|c|c|}
\hline Lubricant & $\begin{array}{l}\text { Nominal contact } \\
\text { pressure }(\mathrm{kPa})\end{array}$ & Surface appearance \\
\hline $\begin{array}{l}\text { Mineral oil } \\
\text { Motor oil }\end{array}$ & $\begin{array}{l}<100 \\
<100\end{array}$ & Very little surface damage \\
\hline $\begin{array}{l}\text { Mineral oil } \\
\text { Motor oil }\end{array}$ & $\begin{array}{l}100-300 \\
100-700\end{array}$ & $\begin{array}{l}\text { Scratches are present } \\
\text { No surface layer formed }\end{array}$ \\
\hline $\begin{array}{l}\text { Mineral oil } \\
\text { Motor oil }\end{array}$ & $\begin{array}{l}300-2800 \\
700-8400\end{array}$ & $\begin{array}{l}\text { Scratches present but finer than above surface. } \\
\text { Surface layer is present in increasing amounts as } \\
\text { the load is increased }\end{array}$ \\
\hline $\begin{array}{l}\text { Mineral oil } \\
\text { Motor oil }\end{array}$ & $\begin{array}{l}2800-6300 \\
8400-10500\end{array}$ & $\begin{array}{l}\text { Fine scratches present. Surface nearly completely } \\
\text { covered by a surface layer }\end{array}$ \\
\hline $\begin{array}{l}\text { Mineral oil } \\
\text { Motor oil }\end{array}$ & $\begin{array}{l}6300-10000 \\
10500-14000\end{array}$ & $\begin{array}{l}\text { Fine scratches present. Surface nearly completely } \\
\text { covered by a surface layer. Wear rate is extremely } \\
\text { high }\end{array}$ \\
\hline
\end{tabular}


layers became visible and there were fewer and less severe scratches. The surface layer apparently provides some protection against the scratching seen in the early part of the test. Also, the surface layer which formed when using mineral oil covered a greater percentage of the test specimen surface than the specimens run with motor oil.

All of the tests performed at loads above $100 \mathrm{kPa}$ produced scratches during the first few minutes in a manner analogous to that observed in fired engines. Therefore the micrographs given in Figs. 11 - 19 describe the observations during early running from both the test machine and the fired engines.

The most important location on the cylinder wall of a fired engine is the TDC position of the top piston ring. As described earlier, the cylinder wall surface in this location from a fired engine was almost completely covered with a dark film. Therefore the simulation criterion used to determine which constant load test best duplicated the wear process in this location was a test specimen with a surface layer that duplicates the physical appearance of the surface layer seen in real engines. The test conditions that satisfied this criterion were a nominal contact pressure of $4900 \mathrm{kPa}$, a speed of 350 cycles $\min ^{-1}$ and mineral oil as the lubricant. A photograph of the surface of a test specimen run for $2 \mathrm{~h}$ under these conditions is shown in Fig. 22. It can be seen that Fig. 22 closely resembles Fig. 20 which is a photograph taken from the TDC position of a fired engine.

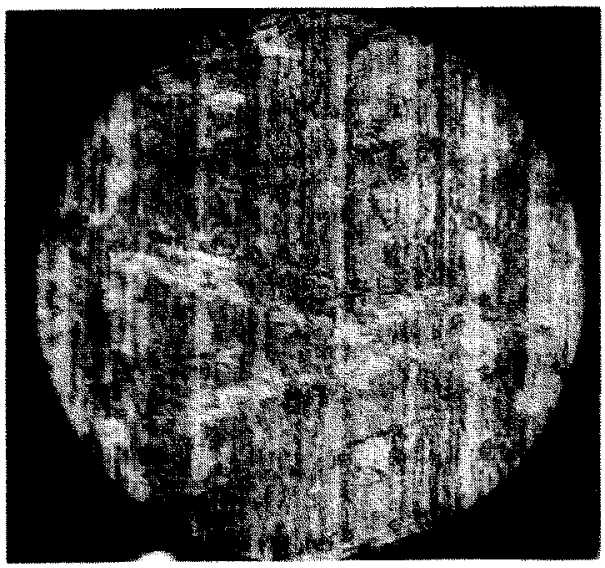

Fig. 22. Test specimen run for $2 \mathrm{~h}$ in the test machine at the operating conditions found to simulate wear at TDC of the top ring (magnification $202 x$ ).

\section{Conclusions}

A laboratory simulator was developed that appears to simulate the progression of surface change in fired engines. It was not operated for the specific purpose of duplicating conditions in an engine. Apparently, it is not necessary to duplicate the temperature, oxidizing atmosphere, contact pressure 
and fluid film thickness of the engine in the simulator. Since the material clearly responds to sliding in the same way in both the engine and the oscillating tester, the oscillating tester is an adequate simulator of the engines we studied.

In the TDC region of the cylinder wall, wear appears to progress in several steps. The cylinder surface begins with a number of cross-hatched grooves with ploughed material built up alongside the grooves. A moving piston ring breaks off some of the ploughed material and uses it to scratch vertical grooves in the cylinder wall. With further wearing all of the ploughed material is removed and the slower wear processes then operate to remove most of the grooves from the surface.

Simultaneous with the grooving there is also the growth of a surface film on the cylinder surface. These may have been identified as the products of degradation of lubricant in the fired engines but the films also appear on surfaces in the lab simulator. From previous work with laboratory devices it has been found that the film is likely to be $\mathrm{Fe}_{3} \mathrm{O}_{4}[43]$ and it functions as a "solid lubricant". Its composition in a fired engine is not known. In either case the oxides that form are removed with sliding and this could be a significant mechanism of slow wear of cylinder walls. Its role in the transition from the break-in type of severe wear to the slow wear mode is not known.

\section{Acknowledgments}

We are grateful to General Motors Manufacturing Development Section and Dr. Chi-hung Shen for financial support, test materials and helpful advice in the course of our research. In addition, Mr. Ken Shier and Mr. Gary Blair of the Cadillac Division of General Motors tested several engines and also provided us with many engine parts and very valuable advice.

\section{References}

1 S. W. Sparrow and T. A. Scherger, Cylinder wear - where and why, SAE Trans, 38 (4) (1936) 117.

2 Y. Nakayama and H. Endo, Effect of finishing grade on the wear of diesel engine cylinder wall, Bull. JSME, 2 (8) (1959) 584.

3 T. S. Sudarshan and S. B. Bhaduri, Wear in eylinder liners, Wear, 91 (1983) 269.

4 S. L. Moore and G. M. Hamilton, The piston ring at top dead center, Proc. Inst. Mech. Eng. London, 194 (1980) 373.

5 R. A. Castleman, A hydrodynamical theory of piston ring lubrication, Physics, 7 (1936) 364.

6 L. L. Ting and J. E. Mayer, Piston ring lubrication and cylinder bore wear analysis theory, J. Lubr. Technol, (July 1974) 305.

7 L. L. Ting and J. E. Mayer, Piston ring and cylinder bore wear analysis - theory verification, J. Lubr. Technol., Paper 73-Lub-27.

8 D. G. Allen, B. R. Dudley, V. Middleton and D. A. Parker, Prediction of cylinder bore oil film thickness in two particular engines, Institution of Mechanical Engineers Conf. on Piston Ring Scuffing, 1975, p. 107. 
9 S. L. Moore and G. M. Hamilton, The starved lubrication of piston rings in a diesel engine, J. Mech. Eng. Sci., 20 (6) (1978) 345.

$10 \mathrm{~K}$. Shin, Y. Tateishi and S. Furuhama, Measurement of oil film thickness, SAE Paper $830068,1983$.

11 J. J. Gumbleton, Piston ring and cylinder wear measurements illustrate the potential and limitations of the radioactive technique, SAE National Automobile Week, Detroit, MI, March 1961, Paper 324A.

12 M. M. Roensch, Observations on cylinder-bore wear, SAE Trans., 40 (3) (1937) 89.

13 B. A. Yates, Recent developments in piston ring materials, SAE Trans., 44 (2) (1939) 49.

14 C. G. Williams, Cylinder wear in gasoline engines, SAE Trans., 38 (5) (1936) 191.

15 Anonymous, Cylinder liner design, Automob. Eng. London, (September 1953) 373.

16 R. D. Wing and $O$. Saunders, Oil film temperature and thickness measurements on the piston rings of a diesel engine, Proc. Inst. Mech. Eng. London, 186 (1972) 1.

$17 \mathrm{~K}$. Fursund, Wear in cylinder liners, Wear, 1 (1957-1958) 104.

$18 \mathrm{~J}$. R. B. Calow and S. R. Epton, Trends in piston ring wear in automotive gasoline engines, Proc. Inst. Mech. Eng. London, 175 (10) (1961) 506.

19 L. Bruni and G. Fazzina, Recent developments aiming at reducing wear rates of cylinder liners in grey iron, SAE' Paper $821084,1982$.

20 R. Munro and G. H. Hughes, Current piston and ring practice and the problem of scuffing in diesel engines, Publication 335,1970, p. 1 (Diesel Engineers and Users Association).

21 M. J. Neale, Piston ring scuffing - a broad survey of problems and practice, Proc. Inst. Mech. Eng. London, 185 (2) (1970 - 1971) 21.

22 A. Dyson, Scuffing - a review, Tribol. Int., (April 1975) 77.

23 K. C. Ludema, A review of scuffing and running-in of lubricated surfaces - with asperities and oxides in perspective, Wear, $100(1984) 315$.

24 D. Clayton and C. H. M. Jenkins, Physical changes in rubbing surfaces on scuffing, Br. J. Appl. Phys. Suppl., 2 (1951) 69.

25 M. D. Rogers, Metallographic characterisation of transformation phases on scuffed cast iron diesel engine components, Tribol. Int., (May 1969) 123.

26 M. D. Rogers, The mechanism of scuffing in diesel engines, Wear, 15 (1970) 105.

27 T. S. Eyre and K. K. Dutta, Some metallurgical aspects of scuffing, Institution of Mechanical Engineers Conf. on Piston Ring Scuffing, 1975.

28 D. Scott, A. I. Smith, J. Tait and G. R. Tremain, Materials and metallurgical aspects of piston ring scuffing, Wear, 33 (1975) 293.

29 T. Wiborg, J. Eriksson and A. Tjernaes, Wear resistance of cast iron cylinder liner materials, Norw. Marit. Res., 1 (1974) 2.

30 T. S. Eyre and A. Baxter, The formation of white layers at rubbing surfaces, Met. Mater, (October 1972) 435.

31 B. D. Grozin and V. F. Iankevich, The structure of white layers, Friet. Wear Mach. USSR, 15 (1962) 143.

$32 \mathrm{~V}$. A. Kislik, The nature of white layers formed on friction surfaces, Frict. Wear Mach. USSR, 15 (1962) 153.

33 G. K. Aue, Scuffing - general review, Institution of Mechanical Engineers Conf. on Piston Ring Scuffing, 1975 , p. 1.

34 G. K. Aue, On mechanism of a piston ring seal, Sulzer Tech. Rev, 1 (1)(1974) 352.

35 T. A. Dow and R. A. Burton, Thermoelastic instability of sliding contact in the absence of wear, Wear, 19 (1972) 315.

36 S. R. Heckman and R. A. Burton, Thermoelastic effects in frictionally heated line contact of slab-like bodies, J. Lubr. Tochnol, $100(1978) 136$.

$37 \mathrm{M}$. O. Teetor, The reduction of piston ring and cylinder wear, SAE Trans, 42 (4) (1938) 152.

38 A. V. Sreenath and N. Raman, Mechanism of smoothing of cylinder liner surface during running-in, Tribol. Int., (April 1976) 55. 
39 R. S. Montgomery, Run-in and glaze formation on gray cast iron surfaces, Wear, 14 (1969) 99.

40 W. Hirst and J. K. Lancaster, Surface film formation and metallic wear, $J$. Appl. Phys., 27 (9) (1956) 1057.

41 J. Sugishita and S. Fuijyoshi, Graphite film formation on grey cast iron surfaces, Wear, 66 (1981) 209.

42 J. Sugishita and S. Fujiyoshi, Variables influencing graphite film formation, Wear, 68 (1981) 7 .

43 S. C. Kang and K. C. Ludema, The "breaking-in" of lubricated surfaces. In K. C. Ludema (ed.), Proc. Int. Conf. on Wear of Materials, April 14-18, 1985, American Society of Mechanical Engineers, New York, 1985.

44 B. J. Taylor and T. S. Eyre, A review of piston ring and cylinder liner materials, Tribol. Int., (April 1979) 79.

45 G. F. Hyde, J. E. Cromwell and W. C. Arnold, Piston ring coating for high performance diesel engines, SAE Paper 670935, 1967.

$46 \mathrm{M}$. M. Roensch, Piston ring coatings and their effect on ring and bore wear, $S A E$ Trans., 46 (5) (1940) 221.

47 G. F. Hyde, J. E. Cromwell and J. H. Barnes, Piston ring coatings for internal combustion engines, SAE Paper 790865, 1979.

48 T. C. Jarrett, Some physical and wear characteristics of porous-chromium-plated rings, SAE Trans., 52 (5) (1944) 222.

$49 \mathrm{~J}$. E. Jackson, Wear-resistant coatings of diesel cylinder liners, $S A E$ Trans, 48 (1) (1941) 28.

50 J. Nadel and T. S. Eyre, Cylinder liner wear in low speed diesel engines, Tribol. Int. (October 1978) 267.

51 J. E. LaBelle, Wear resistance of cast iron components. In C. Lipson and L. V. Colwell (eds.), Handbook of Mechanical Wear, University of Michigan Press, Ann Arbor, MI, $1961, \mathrm{p}, 378$.

52 B. M. Astashkevich and T. V. Larin, Influence of iron microstructure on wear resistance of cylinder liners and piston rings, Russ. Cast. Prod., (January 1975).

$53 \mathrm{~K}$. W. Conner, Surface and shape characteristics of cylinder bores, SAF Trans., 36 (3) (1935) 95 .

$54 \mathrm{~K} \times \mathrm{W}$. Conner, Surface finish related to wear in internal combustion engines, $S A E$ Trans., 43 (2) (1938) 305.

$55 \mathrm{D}$. M. Hesling, A study of typical bore finishes and their effect on engine performance, Lubr. Eng., (October 1963) 414.

56 D. A. Law, Further developments in cylinder bore finishes, SAE Paper 690751, 1969.

57 W. R. Kauten, Diesel engine cylinder liner honing, Honing Technology Clinic, June 8, 1982, Society of Manufacturing Engineers, Paper MR82-938.

$58 \mathrm{~S}$. Eilon and O. A. Saunders, A study of piston-ring lubrication, Proc. Inst. Mech. Eng. London, 171 (1957) 427 .

59 A. de Faro Barros and A. Dyson, J. Inst. Pet. London, 46 (1960) 433.

$60 \mathrm{H}$. W. Tischbein, The friction of piston rings, NACA Tech. Memo. 1069, 1939 (National Advisory Committee on Aeronautics).

61 M. G. El-Sherbiny, Cylinder liner wear, In D. Dowson and C. M. Taylor (eds.), 9th Leeds-Lyon Symp. on Tribology, Leeds, 1982, IPC Science and Technology, Guildford, 1984 .

62 J. E. Willn and P. S. Brett, Piston ring scuffing during running-in - the influence of lubricants and materials, Proc. Inst. Mech. Eng. London, 191 (22) (1977) 241.

63 C. A. Smith and F. A. Davis, Abrasive wear of piston ring and cylinder bore materials, Automot. Eng., 9 (1) (1984) $26 \cdot 28$. 